() Open Access Full Text Article

REVIEW

\title{
Current Perspectives on the Role of Very-Low- Energy Diets in the Treatment of Obesity and Type 2 Diabetes in Youth
}

This article was published in the following Dove Press journal: Diabetes, Metabolic Syndrome and Obesity: Targets and Therapy

\author{
Megan L Gow (D) \\ Anna Pham-Short ${ }^{2}$ \\ Hiba Jebeile (D) \\ Benjamin J Varley (D) $^{\prime}$ \\ Maria E Craig $\mathbb{D}^{3}$ \\ 'The University of Sydney Children's \\ Hospital Westmead Clinical School, \\ Sydney, NSW, Australia; ${ }^{2}$ Institute of \\ Endocrinology and Diabetes, The \\ Children's Hospital at Westmead, Sydney, \\ NSW, Australia; ${ }^{3}$ School of Women's and \\ Children's Health, University of New \\ South Wales, Sydney, NSW, Australia
}

Correspondence: Megan L Gow The University of Sydney Children's Hospital Westmead Clinical School, Sydney, NSW, Australia

Tel +6I 298450000

Fax +6I 298453170

Email megan.gow@health.nsw.gov.au

\begin{abstract}
In both developed and developing countries, pediatric obesity and type 2 diabetes are an increasing public health concern: globally $5.6 \%$ of girls and $7.8 \%$ of boys aged $\geq 5$ years have obesity. The incidence of type 2 diabetes has increased in youth in recent decades and disproportionately affects those from ethnic/racial minority groups and disadvantaged backgrounds. For the treatment of both conditions, conventional lifestyle intervention is frequently ineffective, access to bariatric surgery is very limited and many young people are unsuitable or unwilling to undergo surgery. A very-low-energy diet (VLED) provides a viable alternative and may be effective for weight reduction and improved glycemic control in youth, based on one systematic review. In particular, in the treatment of type 2 diabetes, a chart review and a pilot study both demonstrated that a VLED can reduce the requirement for medications, including insulin, and lead to the remission of diabetes. However, long-term follow-up and safety data remain limited and therefore a VLED is inconsistently recommended by clinical practice guidelines for the treatment of pediatric obesity and type 2 diabetes. In clinical practice, VLED use in children and adolescents is uniquely challenging due to intolerance of expected side effects, difficulty adhering to the highly restrictive diet and difficulty with behaviour change within the current social context and environment. Ultimately, more research, including larger, longer-term trials with comprehensive safety monitoring are required to strengthen the evidence base. This would inform clinical practice guidelines, which may facilitate more widespread utilization of VLED programs in the management of obesity and type 2 diabetes in youth.
\end{abstract}

Keywords: pediatrics, obesity, type 2 diabetes, very-low-energy diet, youth

\section{Introduction}

In both developed and developing countries, pediatric obesity and type 2 diabetes are an increasing public health concern: globally $5.6 \%$ of girls and $7.8 \%$ of boys aged $\geq 5$ years have obesity. ${ }^{1}$ The worldwide incidence of child and adolescent obesity is increasing with an estimated 158 million affected in 2020 and 254 million by $2030 .^{2}$ Population-based epidemiological data for type 2 diabetes in children and adolescents are limited, but largely indicate increasing incidence rates in developed countries in recent decades. ${ }^{3,4}$ In the SEARCH for diabetes in youth study, the US type 2 diabetes incidence increased from 9.0 per 100,000 in 2002-2003 to 13.8 in 2014-2015 in youth aged 10-19 years, which equates to an annual percentage change of $4.8 \% .^{5}$ Incidence of type 2 diabetes is disproportionately higher in youth from certain at-risk groups, including ethnic/racial 
minorities and those from disadvantaged backgrounds. ${ }^{6-9}$ Increasing rates of type 2 diabetes in young people is especially concerning given the earlier onset of related complications and mortality in those with younger compared with older onset of type 2 diabetes. ${ }^{9,10}$ The increasing prevalence of obesity and type 2 diabetes and the poor prognosis of type 2 diabetes in young people pose significant clinical challenges that require effective treatment strategies.

Clinical practice guidelines describe weight loss as a primary goal in the treatment of pediatric obesity in the presence of comorbidities, severe obesity and type 2 diabetes. ${ }^{11,12}$ It is recommended that weight loss be achieved using a lifestyle modification program that incorporates nutrition and physical activity education, encouraging sustained behavior change. ${ }^{11,13}$ In type 2 diabetes, once metabolic stability is achieved, lifestyle intervention with metformin therapy is recommended as first-line treatment. ${ }^{12,14,15}$ Systematic reviews of pediatric obesity treatment demonstrate that conventional lifestyle modification programs lead to modest weight loss in the short-to-medium term. ${ }^{16-18}$ However, many youth with obesity do not respond to conventional treatment, ${ }^{19,20}$ and, similarly, many youth with type 2 diabetes do not respond to traditional diabetes therapy. In the TODAY study, the largest clinical trial conducted to date comparing type 2 diabetes treatment options for 699 10-17 year olds in the US, lifestyle modification with metformin led to meaningful weight loss for only one-third of adolescent participants. ${ }^{21}$ Additionally, one half of participants experienced glycemic control failure after 12-months of treatment. Hence, alternate interventions are required for those who do not respond to conventional therapy.

Bariatric surgery is an effective alternate treatment for both pediatric obesity and type 2 diabetes. ${ }^{9,22,23}$ However, surgery will not be suitable for many young people who may not have the maturity or required family support to comply with the necessary postoperative behaviors. ${ }^{24,25}$ Access to surgery varies worldwide but is limited and expensive. ${ }^{26}$ An intermediate step is needed to bridge the treatment option gap between a conventional lifestyle modification program and bariatric surgery. The emerging evidence base for novel dietary approaches in adults has led to investigation of more intensive dietary therapies for pediatric obesity and type 2 diabetes. One such approach is a very-low-energy diet (VLED). However, there has been little commentary on their role in the treatment of obesity and type 2 diabetes in young people. Hence, the aim of this review is to provide an overview of the current perspectives and literature in this space.

\section{What is a VLED?}

There is no standard definition for a VLED, however, it typically involves an energy intake prescription of $\leq 800$ kcal per day for the purpose of achieving rapid weight loss. $^{27,28}$ A VLED is usually low in carbohydrate (eg, <50 $\mathrm{g} /$ day) and high in quality protein (minimum of $0.8-1.5 \mathrm{~g} /$ $\mathrm{kg}$ body weight per day) in order to preserve lean body mass. ${ }^{29}$ Due to the low carbohydrate content, VLEDs can induce a mild state of ketosis as evidenced by an increase in circulating blood ketone concentration. ${ }^{30}$ This process can aid lean mass preservation and facilitate appetite suppression. $^{30,31}$ A high calorie-free fluid intake (eg, 2 $\mathrm{L}$ per day) is also recommended. Typically, a VLED is prescribed as a short-term approach (eg, 8-12 weeks), under the guidance of a trained health professional.

VLEDs can be administered as either a meal replacement or food-based diet. Meal replacements are more commonly used whereby the individual replaces some or all foods with commercially formulated products eg, shakes, soups, bars or desserts. $^{29,31}$ Many commercially available products exist and there is wide variability between products in terms of nutritional content, nutritional adequacy and cost. ${ }^{32}$ Several are nutritionally complete in line with adult requirements due to supplementation with essential vitamins and minerals, giving rise to their popularity. ${ }^{33}$ However, a multivitamin may be required to meet nutritional adequacy in children and adolescents due to increased micronutrient requirements associated with growth.

A food-based VLED is more commonly termed a "protein sparing-modified fast" in the literature. Compared to the advised minimum protein intake of $0.8-1.5 \mathrm{~g} / \mathrm{kg}$ body weight per day for a VLED, more protein is prescribed when using a food-based VLED with pediatric obesity treatment studies reporting protein prescription typically in the range of $1.5-2 \mathrm{~g} /$ $\mathrm{kg}$ body weight/day, but as high as $3 \mathrm{~g} / \mathrm{kg}$ body weight/day. ${ }^{27}$ Vitamin and mineral supplementation eg, potassium chloride, calcium carbonate, vitamin $\mathrm{K}$, magnesium, and sodium, are also typically used in conjunction with the diet to enhance nutritional adequacy. ${ }^{27}$

\section{Systematic Review of VLED in Pediatrics}

One systematic review in 2019 evaluated the use of VLEDs in young people with obesity and type 2 diabetes. ${ }^{27}$ This review identified 24 studies that used a VLED program ( $\leq 800 \mathrm{kcal} /$ day) for weight management in a total of 674 children and adolescents, aged five to 18 years. All study 
designs were included to allow for evaluation of the safety of VLEDs in this population and have been summarized in Table 1. Meta-analysis of 20/24 included studies indicated that a VLED program of 3 to 20 weeks duration resulted in a significant mean (SD) weight loss of 10.1 (0.7) kg suggesting the overall short-term effectiveness of a VLED program for weight loss (Figure 1A). At latest follow-up (20 weeks to 14.5 months from baseline), weight loss was 5.3 (1.4) $\mathrm{kg}$ in seven studies (Figure 1B). This is more weight loss compared with the weight loss reported at latest follow-up in the 2017 Cochrane reviews of the impact of conventional pediatric multidisciplinary weight management interventions. ${ }^{17,18}$ In these reviews mean weight change was $-1.45 \mathrm{~kg}(95 \% \mathrm{CI}$, -1.88 to $-1.02, \mathrm{P}<0.001)$ for children ${ }^{18}$ and $-3.67 \mathrm{~kg}(95 \%$ CI, -5.21 to $-2.13, \mathrm{P}<0.001$ ) for adolescents. ${ }^{17}$ However, the Cochrane reviews included studies that recruited children and adolescents with both overweight and obesity, compared with obesity only in the VLED review. Additionally, the Cochrane reviews included a follow-up period ranging from 6-months up to 3-years, compared with 20-weeks to 14.5-months in the VLED review. Despite these differences, the overall findings from the 2019 systematic review highlight that a VLED program is an effective intervention for weight loss and may be a feasible alternate treatment option for young people (Table 2).

\section{VLED for Obesity}

Of the 24 published studies identified by the 2019 systematic review, 22 utilized a VLED program to treat pediatric obesity specifically. ${ }^{27}$ Only two of these studies were published after 2000 highlighting a lack of recent data in this area. To the best of our knowledge, there have been no relevant trials published since the 2019 systematic review.

\section{VLED for Type 2 Diabetes}

The 2019 systematic review identified two published studies that implemented a VLED in young people with type 2 diabetes. One was a chart review ${ }^{34}$ and the other a pilot intervention study in eight participants. ${ }^{35}$ Both studies demonstrated significant weight loss and improvements in multiple aspects of diabetes, including improved glycemic control and reduced medication use. In particular, both studies reported that all except one participant receiving insulin therapy at

Table I Description of Published Very-Low-Energy Diet Intervention Trials for Young People with Obesity and/or Type 2 Diabetes

\begin{tabular}{|c|c|c|c|}
\hline & Food-Based VLED Interventions, $n=17$ & $\begin{array}{l}\text { Formula-Based VLED } \\
\text { Interventions, } n=6\end{array}$ & $\begin{array}{l}\text { VLED Type } \\
\text { Not Stated, } \\
n=I\end{array}$ \\
\hline Year of publication & $\begin{array}{l}1980 s(n=2), 1990 s(n=12), 2000 s(n=2), 2010 s \\
(n=1)\end{array}$ & $1980 s(n=5), 2010 s(n=1)$ & 1997 \\
\hline Country of study & USA $(n=\mid 2)$, Italy $(n=3)$, Austria $(n=2)$ & $\begin{array}{l}\text { Austria }(n=4), \text { USA }(n=1), \\
\text { Australia }(n=1)\end{array}$ & Italy \\
\hline Study type & $\begin{array}{l}\text { Chart review }(n=2) \text {; pre-post }(n=12) \text {; non- } \\
\text { randomised comparison }(n=2) ; \operatorname{RCT}(n=1)\end{array}$ & $\begin{array}{l}\text { Pre-post }(n=4) \text {; non- } \\
\text { randomised comparison }(n=2)\end{array}$ & RCT \\
\hline Sample size (range of included studies) & 6 to 87 & 8 to 16 & 103 \\
\hline Participant age (range of included studies) & 5 to 18 years & 7 to 16 years & $\begin{array}{l}\text { mean } \pm S D: \\
15.4 \pm 0.2 \text { years }\end{array}$ \\
\hline Inclusion criteria & $\begin{array}{l}\text { Obesity/severe obesity }(n=16) \text {; obesity and } \\
\text { type } 2 \text { diabetes }(n=1)\end{array}$ & $\begin{array}{l}\text { Obesity/severe obesity }(n=5) \\
\text { obesity and type } 2 \text { diabetes } \\
(n=I)\end{array}$ & Severe obesity \\
\hline $\begin{array}{l}\text { Intervention duration; follow-up from } \\
\text { baseline (number of studies including } \\
\text { follow-up) }\end{array}$ & $\begin{array}{l}3 \text { weeks to "up to" } 26 \text { weeks (until goal weight } \\
\text { achieved); } 20 \text { weeks to "up to" } 5 \text { years }(n=10)\end{array}$ & $\begin{array}{l}3 \text { weeks to } 5 \text { months; } 34 \text { week } \\
(n=I)\end{array}$ & $\begin{array}{l}2 \text { months; no } \\
\text { follow up }\end{array}$ \\
\hline $\begin{array}{l}\text { Range of retention rates post intervention; } \\
\text { follow up }\end{array}$ & $75-100 \% ; 50-70 \%$ & $63-100 \% ; 63 \%$ & NR \\
\hline
\end{tabular}

Note: Data from Andela et al. ${ }^{27}$

Abbreviation: NR, not reported. 
A Study name

Bakhach et al. 2016 6mo Figueroa-Colon et al. 1993 14.5mo Follow-up Figueroa-Colon et al. $19966 \mathrm{mo}$ Gow et al. 2017 34wk Sothern et al. 1999 1y Sothern et al. 2000 1y Willi et al. 1998 20wk

\begin{tabular}{lccccc} 
Time point & \multicolumn{5}{c}{ Statistics for each study } \\
\cline { 3 - 5 } & $\begin{array}{l}\text { Difference Standard Lower Upper } \\
\text { in means }\end{array}$ & error & limit & limit & p-Value \\
Follow-up & -11.2 & 3.4 & -17.8 & -4.5 & 0.00 \\
Follow-up & -1.3 & 2.6 & -6.5 & 3.9 & 0.62 \\
Follow-up & -5.6 & 2.0 & -9.6 & -1.6 & 0.01 \\
Follow-up & -7.9 & 12.2 & -31.9 & 16.1 & 0.52 \\
Follow-up & -8.4 & 2.3 & -13.0 & -3.8 & 0.00 \\
Follow-up & -6.1 & 3.4 & -12.9 & 0.7 & 0.08 \\
Follow-up & -2.3 & 1.2 & -4.6 & 0.0 & 0.05 \\
& -5.3 & 1.4 & -8.0 & -2.5 & 0.00
\end{tabular}

Difference Standard Lower Uppe

in means error limit limit $p$-Value

Bakhach et al. 2016 6mo

Figueroa-Colon et al. 1993 14.5mo Follow-up

Figueroa-Colon et al. $19966 \mathrm{mo}$

Gow et al. 2017 34wk

Sothern et al. 1999 1y

Sothern et al. 2000 1y

Willi et al. 1998 20wk

$\begin{array}{ccccc}-11.2 & 3.4 & -17.8 & -4.5 & 0.00 \\ -1.3 & 2.6 & -6.5 & 3.9 & 0.62 \\ -5.6 & 2.0 & -9.6 & -1.6 & 0.01 \\ -7.9 & 12.2 & -31.9 & 16.1 & 0.52 \\ -8.4 & 2.3 & -13.0 & -3.8 & 0.00 \\ -6.1 & 3.4 & -12.9 & 0.7 & 0.08 \\ -2.3 & 1.2 & -4.6 & 0.0 & 0.05 \\ -5.3 & 1.4 & -8.0 & -2.5 & 0.00\end{array}$

$\begin{array}{llllll}\text { Follow-up } & -5.6 & 2.0 & -9.6 & -1.6 & 0.01\end{array}$

$\begin{array}{llllll}\text { Follow-up } & -7.9 & 12.2 & -31.9 & 16.1 & 0.52\end{array}$

$\begin{array}{llllll}\text { Follow-up } & -8.4 & 2.3 & -13.0 & -3.8 & 0.00\end{array}$

$\begin{array}{llllll}\text { Follow-up } & -6.1 & 3.4 & -12.9 & 0.7 & 0.08\end{array}$

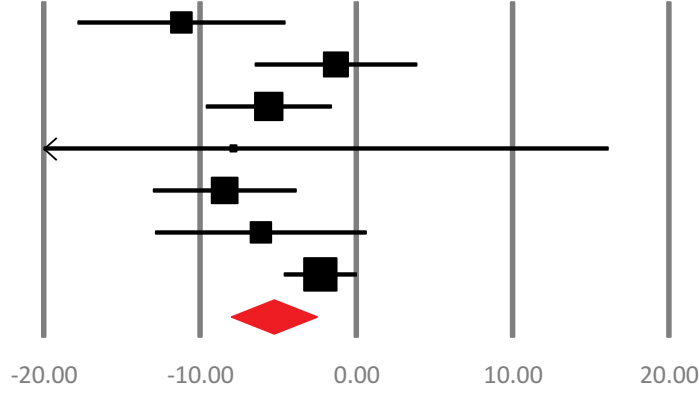

Weight loss (kg) Weight gain $(\mathrm{kg})$
Difference in means and $95 \% \mathrm{CI}$

20.00

$\begin{array}{llllll}\text { Follow-up } & -2.3 & 1.2 & -4.6 & 0.0 & 0.05\end{array}$

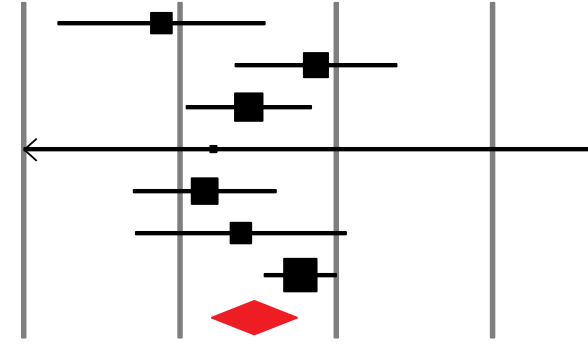

10.00

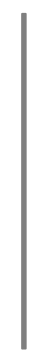

20.00

\section{Weight loss (kg) Weight gain (kg)}

Figure I (A) Meta-analysis of weight loss immediately following a very-low-energy diet intervention. (B) Meta-analysis of weight loss at latest follow-up following a very-low -energy diet intervention. Reproduced with permission from Andela S, Burrows TL, Baur LA, Coyle DH, Collins CE, Gow ML. Efficacy of very low-energy diet programs for weight loss: a systematic review with meta-analysis of intervention studies in children and adolescents with obesity. Obes Rev. 20I9;20(6):87I-882; () 20I9 World Obesity Federation. ${ }^{27}$

commencement of the VLED program ceased insulin and remained insulin-free for the duration of the chart review period/trial. ${ }^{35}$ Improvements in glycemia were also significant, including reduction in glycated hemoglobin $(\mathrm{HbAlc})$ from $8.8 \%$ (SD 0.6 ) to $7.4 \%(0.6)$ in the chart review ${ }^{34}$ and normalisation of fasting glucose, 2-hour glucose and $\mathrm{HbAlc}$ in four of five study completers in the pilot study. ${ }^{35}$ The one completing participant in the pilot study that did not have remission of their diabetes (defined ${ }^{14}$ as $\mathrm{HbAlc}<6.5 \%,(<48 \mathrm{mmol} / \mathrm{mol}$ ), fasting plasma glucose $<7.0 \mathrm{mmol} / \mathrm{l}$ and $2 \mathrm{~h}$ post-glucose load plasma glucose $<11.1 \mathrm{mmol} / \mathrm{l}$ ) had type 2 diabetes for the longest duration ( 3.25 years). The authors of the pilot study suggested that implementation of a VLED program early following diagnosis of type 2 diabetes may be an important consideration when aiming for diabetes remission, recommending a window of within 6-months from diagnosis. ${ }^{35}$

While limited, the data from these two small studies suggest that VLED programs may be particularly useful for the treatment of type 2 diabetes in youth. However, there is no long-term data in this area, and little is known about whether remission of diabetes is maintained beyond 6-months post intervention. It is likely that some form of continued intervention following the initial VLED program will be required to maintain benefits attained, including interventions focused on sustained nutrition and physical activity behavior change. 
Table 2 Evidence and Knowledge Gaps for the Use of Very-Low-Energy Diets in Youth

\begin{tabular}{|c|c|}
\hline $\begin{array}{l}\text { What is known about VLED use in } \\
\text { obesity? }\end{array}$ & - Leads to short-term weight loss \\
\hline $\begin{array}{l}\text { What is known about VLED use in } \\
\text { type } 2 \text { diabetes? }\end{array}$ & $\begin{array}{l}\text { - Improves glycemic control, including potential remission } \\
\text { - Can reduce the need for medication }\end{array}$ \\
\hline Areas for future research & $\begin{array}{l}\text { - Long-term studies } \\
\text { - Larger studies } \\
\text { - Studies that include a control group } \\
\text { - Collection and reporting of safety data including side effects, growth, cardiac function, psycho-behavioral } \\
\text { outcomes and acceptability of the diet }\end{array}$ \\
\hline
\end{tabular}

\section{VLEDs in Adults}

The adult literature on the use of VLEDs in the treatment of obesity and type 2 diabetes is more extensive. The longterm effectiveness of a VLED for weight loss compared with conventional approaches was reported in a 2016 systematic review of the literature which reported that a VLED program resulted in $3.9 \mathrm{~kg}$ more weight loss at 1 year, $1.4 \mathrm{~kg}$ more weight loss at 2 years, and $1.3 \mathrm{~kg}$ more weight loss at 3 to 5 years. ${ }^{36}$ Additional benefits have been described including a 2019 systematic review, which reported that subjective depressive symptoms improved following a VLED program that was at least 8 weeks long and included behavioral therapy and low intensity exercise. ${ }^{37}$ Furthermore, a systematic review of three trials evaluating the experiences of people using a VLED program for weight loss found that a VLED program was well accepted and positively viewed by participants. ${ }^{38}$

The Diabetes Remission Clinical Trial (DiReCT) in the UK is a landmark study investigating the effectiveness of a VLED program to treat type 2 diabetes in adults that has received considerable media attention worldwide. Following on from several smaller studies, ${ }^{39-41}$ the DiReCT trial demonstrated remission of type 2 diabetes (defined as HbAlc less than $6.5 \%(48 \mathrm{mmol} / \mathrm{mol})$ ) in almost half of the participants following a VLED in a primary care setting, with remission sustained up to 24months from baseline. ${ }^{42,43}$ The DiReCT study has also published cost-effectiveness data demonstrating that, compared to standard care, a VLED intervention to treat type 2 diabetes is more cost effective, due to related cost savings from achieving diabetes remission, even if only temporary. ${ }^{44}$ Such cost saving benefits may be greater in the adolescent population for whom the progression of diabetes is more rapid with earlier onset of complications.
The DiReCT study has also published work describing the proposed mechanism for type 2 diabetes remission related to weight loss achieved during a VLED. ${ }^{45}$ They demonstrate that individuals who adhere to the VLED and achieve rapid weight loss have reductions in triglyceride production by the liver and reduced pancreatic fat that leads to improved beta-cell function and remission of diabetes. ${ }^{45}$ If weight loss is maintained, levels of triglyceride production and pancreatic fat stabilize at these lower levels, and diabetes remission is sustained during the 2-year follow-up period. Re-emergence of type 2 diabetes was associated with weight re-gain, increased production of triglyceride by the liver, increased pancreatic fat and deterioration of beta-cell function. The importance of weight loss for diabetes remission was highlighted by a 2020 study demonstrating that a VLED program is as successful at achieving type 2 diabetes remission as bariatric surgery when similar weight loss is achieved. ${ }^{46}$ Similarly, a 2020 systematic review of 18 studies reported that, compared to bariatric surgery, VLEDs offered comparable effects on weight loss, glycemic control, triglycerides, and insulin resistance and suggested that a VLED approach be used for individuals unsuitable or unwilling to undergo surgery. ${ }^{47}$

The findings from the DiReCT study led to the rollout of a VLED program in primary care in the UK, in what was termed a "diabetes remission service". ${ }^{48}$ Despite the growing acceptance of the role of a VLED program for weight loss and type 2 diabetes treatment in adults, there remains significant hesitation in their use in youth (see sections, VLEDs in Clinical Practice and Safety of VLEDs in Youth). Although the available evidence appears promising, it remains limited compared with adult studies. 


\section{Guidelines for Use of VLEDs in Children and Adolescents}

A 2020 review of guidelines for the dietary management of pediatric obesity found that all 28 guidelines recommend a multicomponent family-based lifestyle intervention including education relating to dietary change, physical activity and behavior change strategies as firstline therapy. ${ }^{11,49}$ If improvements in weight status and/or cardiometabolic health are not attained using this approach, progression to a more structured and intensive intervention is recommended.

In six of the 28 guidelines identified in the 2020 review, a food-based or meal replacement VLED is proposed as one of the intensive dietary strategies recommended to induce weight loss in children and adolescents with obesity and related comorbidity or severe obesity. ${ }^{11}$ Specific guidance on the use of a VLED in clinical practice for pediatrics is provided in only one set of guidelines published by the Academy of Nutrition and Dietetics. These guidelines recommend a short-term VLED prescription (10-12 weeks) that is $600-800 \mathrm{kcal} /$ day, high in lean protein ( 1.5 to $2.0 \mathrm{~g} / \mathrm{kg}$ of ideal body weight), 20-25 g/day of carbohydrate, with $2 \mathrm{~L}$ /day of calorie-free fluid and a daily multivitamin, prescribed under the supervision of a multidisciplinary team. ${ }^{28}$ A VLED may provide an intermediate step between conventional lifestyle intervention and bariatric surgery, particularly for adolescents with severe obesity. ${ }^{11}$ However, the paucity of recent trials and lack of long-term data has limited the inclusion of this dietary approach into clinical practice guidelines. A broader evidence base is required to inform future guidelines for the management of pediatric obesity.

Guidelines for the management of type 2 diabetes in youth are largely based upon obesity management guidelines. A family-based multicomponent lifestyle intervention, delivered by a pediatric dietitian experienced in the management of type 2 diabetes, is recommended alongside medical management of type 2 diabetes in youth, often aiming for weight loss. ${ }^{12,14,15,50-52}$ The American Diabetes Association ${ }^{14}$ recommends intensive weight management as a component of the treatment plan for youth with type 2 diabetes but does not recommend a specific dietary approach. A carefully monitored and individualized VLED-based dietary intervention is recommended in some guidelines as a short-term (8-12 weeks) approach to achieve rapid weight loss and improve glycemic control in adolescents with obesity and type 2 diabetes. ${ }^{50-52}$ Overall, guidelines highlight a lack of evidence relating to specific dietary approaches beneficial for the management of type 2 diabetes in youth, representing an important area for further research. $^{14,50-52}$

Guidelines for the use of dietary interventions in the management of pediatric obesity recommend screening for eating disorders prior to initiating treatment. ${ }^{49}$ Similarly, the Australian Paediatric Endocrine Group recommends screening for disordered eating prior to the use of a VLED in adolescents with type 2 diabetes. ${ }^{50}$ To the best of our knowledge, self-report questionnaires designed to screen for eating disorder pathology have not been well validated in children or adolescents with obesity or those seeking obesity treatment. A number of screening procedures have been suggested and are yet to be evaluated. ${ }^{53}$

\section{VLEDs in Clinical Practice}

The hesitation in the use of VLED programs for the treatment of obesity and type 2 diabetes in young people likely, at least in part, stems from the unique clinical challenges that this age presents to health care professionals.

\section{Motivation}

Behaviour change within the current social context and environment is difficult. Yet on top of this, the adolescent brain may also lack the maturity to comprehend the future health benefits of weight loss and focus instead on immediate gratification. ${ }^{54}$ This is supported by a 2018 review examining the viewpoints of adolescents with obesity who attended a weight management intervention which found that the motivation to lose weight was more often related to wanting to be "normal" and socially desirable as opposed to preventing health sequelae.$^{55}$ Goals and motivators for weight loss thus should be meaningful to the adolescent in the short-term. These may include the reduction in medication usage, even if temporary, or motivators such as increased clothing choices to attend social gatherings, reduced bullying, fewer unwelcome comments by family members, and material rewards for weight loss such as jewellery, games, or outings. Clinicians need to harness such motivating factors, utilizing motivational interviewing techniques, to assist the adolescent with acceptance of and adherence to this challenging energy restriction. 


\section{Side Effects}

The low carbohydrate content of a VLED, and associated mild ketosis, can result in the manifestation of several expected but unpleasant side effects including constipation, fatigue, nausea, headaches or dizziness ${ }^{56}$ and halitosis. Adolescents should be pre-warned of these, usually transient, side effects and encouraged to persevere with the VLED. Indeed, a high prevalence of similar side effects including fatigue, headaches and muscle cramps have been observed in adolescents presenting with obesity. ${ }^{57}$ Therefore, it is unclear whether all side effects reported when following a VLED are solely related to the diet. The addition of a stool-bulking dietary fibre such as psyllium husk at commencement of a VLED may alleviate constipation. ${ }^{58}$ Ensuring adequate fluid intake of an additional 2 litres in addition to the water added to the VLED products also aids in preventing constipation and headaches.

\section{Barriers and Challenges to VLED Adherence}

Adherence to VLEDs in adults is high ${ }^{59}$ and easier than anticipated. $^{58}$ However, despite the previously described treatment advantages for young people, there are several barriers to their use in clinical practice (Table 3 ) and adherence may be more challenging compared to adults. In our clinical experience with youth with confirmed type 2 diabetes (aged 13-16 years at VLED commencement), common challenges with adherence to a VLED include taste or textural issues, limited variety of products, missing "real food", and feeling isolated whilst family members or friends consume whole foods around them. Similar to adult studies, ${ }^{38}$ adolescents also report difficulty attending social events while following a VLED. Ensuring adequate water is added to shakes or soups for a thinner consistency, or cooler water, may increase palatability. Additionally, a variety of shakes, bars, soups, and puddings are available on the market and trialling different brands may reduce taste fatigue. ${ }^{38}$

Some families may be faced with financial constraints, therefore the perceived added cost of purchasing VLED products in addition to the usual grocery bill may be a barrier to commencing or adhering to a VLED program. However, replacing all meals and snacks with meal replacement products available in Australia costs less than "real food", based on average per capita food expenditure. $^{32}$

\section{Facilitators to VLED Adherence}

There are also several strategies that healthcare professionals and families can utilize to facilitate the young person's ability to adhere to a VLED (Table 3). The provision of VLED products by the treating team and frequent contact with a healthcare professional facilitate low attrition rates. ${ }^{58}$ Similar to what is reported in adult studies, in our clinical practice we have observed successful maintenance of the VLED when family members and friends are supportive of the adolescent by undertaking the diet with them, providing encouragement and/or not offering any additional foods. ${ }^{38}$ Adolescents enjoy using technology as part of weight management interventions, therefore the use of calorie counting phone applications may assist adherence to the $800 \mathrm{kcal}$ per day limit. ${ }^{55}$ Additionally, a combination of meal replacements and a food-based meal that is high in protein and non-starch vegetables adds variety and may increase palatability and acceptability. Similar to what has been described in a review synthesizing qualitative research on the experiences of adults with overweight or obesity using VLEDs for weight loss, ${ }^{38}$ adherence may also be facilitated by meal planning, pre-preparing vegetables, drinking lots of water, navigating the practicalities of social outings, including looking at menu items in advance, and

Table 3 Potential Barriers to and Facilitators of the Use in Clinical Practice of Very-Low-Energy Diets to Treat Youth with Obesity and/or Type 2 Diabetes

\begin{tabular}{|l|l|}
\hline Barriers & Facilitators \\
\hline - Difficult to adhere to calorie restriction & - Frequent contact with health professional \\
- Potential safety concerns not adequately addressed in research to & - Provision of VLED products \\
date & - Support from family and peers \\
- Diet acceptability, ie limited food options and taste of meal & - Technology, ie calorie counting phone applications \\
replacements & - Well thought out meal plans \\
- Perceived unaffordability of meal replacement products & - High water consumption \\
- Difficulty attending social events & - Planning for social outings \\
\hline
\end{tabular}


incorporating options such as no sugar soft drinks or flavored waters.

\section{Safety of VLEDs in Youth}

Weight loss in children and adolescents is contentious due to concerns regarding possible impacts on psychosocial health. Indeed, children and adolescents with obesity and/ or type 2 diabetes present with a range of psychosocial comorbidities including reduced quality of life and selfesteem and increased binge eating and depressive symptoms. ${ }^{57,60}$ However, a series of systematic reviews conducted by our team suggests improvements in psychosocial outcomes following health professional-led pediatric obesity treatment. ${ }^{61-63}$ Furthermore, the 2017 pilot study investigating the feasibility of using a VLED in the treatment of adolescents with type 2 diabetes also demonstrated improved quality of life following the intervention. ${ }^{35}$ In adults, the DiReCT study showed that behavioral strategies are an important aspect of administering a VLED. ${ }^{42}$ Together, these findings highlight the need for an adult or young person to engage with a health professional when undertaking a VLED. Many adolescents with severe obesity have a weight that is beyond a healthy adult weight, emphasizing the need for weight loss in this group. In particular, weight loss is indicated in the presence of type 2 diabetes and may facilitate remission of diabetes.

The application specifically of a VLED for weight loss has additional concerns due to the restrictive nature of the diet. In addition to common expected side effects of a VLED, of major concern was the sudden deaths that were reported in adult studies published in the 1970s and 1980s following VLED use. ${ }^{64-66}$ It is likely that these deaths were related to severe nutritional inadequacies that are avoidable now due to the availability of nutritionally complete meal replacements. The 2019 systematic review evaluating studies implementing a VLED program for weight loss in children and adolescents found that safety was poorly described by included studies and suggested that future studies should ensure comprehensive safety data is collected and reported. ${ }^{27}$ Despite the paucity of safety data, available data does not suggest that there are safety issues associated with the use of VLED programs to treat obesity and/or type 2 diabetes in youth. ${ }^{27}$ However, long-term data are not available.

Nutritional inadequacies are common in restrictive diets, especially in children and adolescents who have increased requirements for several nutrients. ${ }^{67}$ Although a VLED represents a severe energy restriction, VLEDs are more commonly administered as meal replacements that are nutritionally complete. This is extremely advantageous, especially in children and adolescents who typically have a more narrow range of preferred food options. However, there are not any commercially available meal replacement products that have been developed based on the increased nutrient requirements of children and adolescents. Protein content in particular can vary between meal replacement products and should be calculated based on individual requirements. ${ }^{32}$ This should be considered when administering a VLED in a young person, with extra care taken to ensure that the prescribed diet is nutritionally complete, and consideration of the use of a multivitamin if the consumption of non-starchy vegetables is low. This emphasizes the need for dietitian input in VLED delivery in a young person with obesity and/or type 2 diabetes.

The Fast Track to Health study, currently underway in Sydney and Melbourne is conducting a 4-week VLED as a kickstart for weight loss in their trial comparing the effectiveness of an intermittent energy restricted diet and a standard hypocaloric diet approach. ${ }^{68}$ This trial is collecting VLED safety data, including multiple psychobehavioral parameters, so will assist in addressing the literature gap on the safety of a VLED in adolescents.

\section{Future Research}

Although the data reported to date appear promising, the two trials in type 2 diabetes participants (one pilot study of $\mathrm{n}=8$ and a chart review) and paucity of obesity treatment trials since 2000 (only two) do not provide sufficient evidence to support recommending a VLED program as a primary treatment strategy in clinical practice guidelines. Further investigation into the effectiveness of a VLED program to treat pediatric obesity and type 2 diabetes is needed in the form of larger, more robust clinical trials with an appropriate non-VLED treatment control group. Future trials should collect data on expected side-effects, growth, cardiac function, psychological wellbeing and acceptability of the diet to confirm the safety and feasibility of VLEDs in youth. Data collection should also continue beyond the intervention period to assess longterm safety and efficacy of VLED programs.

\section{Recommendations for Clinical Practice}

VLEDs appear to be a safe and effective method of short-term weight reduction when conducted under health professional 
supervision. In the absence of usual carbohydrate intake, particular caution should be taken for youth with type 2 diabetes treated with insulin or other hypoglycemic agents. Input from a diabetes team is required to titrate medications and monitor for adverse outcomes including hypoglycemia. Involvement of a dietitian is highly recommended to ensure nutritional adequacy of the diet in the context of a very low calorie intake.

An important consideration for pediatric obesity treatment is that, if conventional treatment has been unsuccessful, a VLED may serve as an intermediate step between conventional lifestyle therapy and bariatric surgery. However, in pediatric type 2 diabetes treatment, a VLED program appears most effective if administered as close as possible to diagnosis, preferably within 6-months, with the potential to reverse the pathology of type 2 diabetes, at least in the short-term. Incorporation of the available evidence base for the use of VLED programs into clinical practice guidelines would be helpful to support the appropriate use in these populations. Details of diet composition, as well as suggestions for health professional monitoring should also be included in guidelines to direct clinicians on how to safely administer a VLED.

\section{Conclusions}

Available data suggest that, for the treatment of youth with obesity, VLEDs are effective for weight loss and have additional benefits for the treatment of type 2 diabetes including improved glycemic control and reduced medication requirements. However, lack of sufficiently powered, long-term trials and limited recent data, including comprehensive safety monitoring, contributes to hesitation of their use in clinical practice.

\section{Abbreviations}

DiReCT, The Diabetes Remission Clinical Trial; HbAlc, glycated haemoglobin; VLED, very-low-energy diet.

\section{Disclosure}

MLG is supported by a NHMRC Early Career Fellowship (APP1158876); MEC is supported by a NHMRC practitioner fellowship (APP1136735); BV is supported by a Research Training Program Stipend (The University of Sydney) and a Charles Perkins Centre top-up scholarship (The University of Sydney); HJ is supported by the Sydney Medical School Foundation. The authors report no other conflicts of interest in this work.

\section{References}

1. N. C. D. Risk Factor Collaboration. Worldwide trends in body-mass index, underweight, overweight, and obesity from 1975 to 2016: a pooled analysis of 2416 population-based measurement studies in 128.9 million children, adolescents, and adults. Lancet. 2017;390 (10113):2627-2642.

2. Lobstein T, Brinsden H. Atlas of Childhood Obesity. London: World Obesity Federation; 2019.

3. Mayer-Davis EJ, Kahkoska AR, Jefferies C, et al. ISPAD clinical practice consensus guidelines 2018: definition, epidemiology, and classification of diabetes in children and adolescents. Pediatr Diabetes. 2018;19(Suppl 27):7-19. doi:10.1111/pedi.12773

4. Tran F, Stone M, Huang CY, et al. Population-based incidence of diabetes in Australian youth aged 10-18 yr: increase in type 1 diabetes but not type 2 diabetes. Pediatr Diabetes. 2014;15 (8):585-590. doi:10.1111/pedi.12131

5. Divers J, Mayer-Davis EJ, Lawrence JM, et al. Trends in incidence of type 1 and type 2 diabetes among youths - selected counties and Indian reservations, United States, 2002-2015. MMWR Morb Mortal Wkly Rep. 2020;69(6):161-165. doi:10.15585/mmwr.mm6906a3

6. Chen L, Magliano DJ, Zimmet PZ. The worldwide epidemiology of type 2 diabetes mellitus-present and future perspectives. Nat Rev Endocrinol. 2011;8(4):228-236. doi:10.1038/nrendo.2011.183

7. Zeitler P, Fu J, Tandon N, et al. ISPAD clinical practice consensus guidelines 2014. Type 2 diabetes in the child and adolescent. Pediatr Diabetes. 2014;15(Suppl S20):26-46. doi:10.1111/pedi.12179

8. Mayer-Davis EJ, Lawrence JM, Dabelea D, et al. Incidence trends of type 1 and type 2 diabetes among youths, 2002-2012. N Engl J Med. 2017;376(15):1419-1429. doi:10.1056/NEJMoa1610187

9. Viner R, White B, Christie D. Type 2 diabetes in adolescents: a severe phenotype posing major clinical challenges and public health burden. Lancet. 2017;389(10085):2252-2260. doi:10.1016/S01406736(17)31371-5

10. Magliano DJ, Sacre JW, Harding JL, Gregg EW, Zimmet PZ, Shaw JE. Young-onset type 2 diabetes mellitus - implications for morbidity and mortality. Nat Rev Endocrinol. 2020;16(6):321-331. doi:10.1038/s41574-020-0334-z

11. Alman KL, Lister NB, Garnett SP, Gow ML, Aldwell K, Jebeile H. Dietetic management of obesity and severe obesity in children and adolescents: a scoping review of guidelines. Obes Rev. 2020;22. doi:10.1111/obr.13132

12. Zeitler P, Arslanian S, Fu J, et al. ISPAD clinical practice consensus guidelines 2018: type 2 diabetes mellitus in youth. Pediatr Diabetes. 2018;19(Suppl 27):28-46. doi:10.1111/pedi.12719

13. Steinbeck KS, Lister NB, Gow ML, Baur LA. Treatment of adolescent obesity. Nat Rev Endocrinol. 2018;14(6):331-344. doi:10.1038/ s41574-018-0002-8

14. Arslanian S, Bacha F, Grey M, Marcus MD, White NH, Zeitler P. Evaluation and management of youth-onset type 2 diabetes: a position statement by the American Diabetes Association. Diabetes Care. 2018;41(12):2648-2668. doi:10.2337/dci18-0052

15. National Institute for Health and Care Excellence. Diabetes (type 1 and type 2) in children and young people: diagnosis and management; 2015. Available from: https://www.nice.org.uk/gui dance/ng18/resources/diabetes-type-1-and-type-2-in-children-andyoung-people-diagnosis-and-management-pdf-1837278149317. Accessed September 11, 2020.

16. Ho M, Garnett SP, Baur L, et al. Effectiveness of lifestyle interventions in child obesity: systematic review with meta-analysis. Pediatrics. 2012;130(6):e1647-e1671. doi:10.1542/peds.2012-1176

17. Al-Khudairy L, Loveman E, Colquitt JL, et al. Diet, physical activity and behavioural interventions for the treatment of overweight or obese adolescents aged 12 to 17 years. Cochrane Database Syst Rev. 2017;6:CD012691. 
18. Mead E, Brown T, Rees K, et al. Diet, physical activity and behavioural interventions for the treatment of overweight or obese children from the age of 6 to 11 years. Cochrane Database Syst Rev. 2017;6:CD012651.

19. Gow ML, Baur LA, Ho M, et al. Can early weight loss, eating behaviors and socioeconomic factors predict successful weight loss at 12- and 24-months in adolescents with obesity and insulin resistance participating in a randomised controlled trial? Int J Behav Nutr Phys Act. 2016;13:43. doi:10.1186/s12966-016-0367-9

20. Gross AC, Kaizer AM, Kelly AS, et al. Long and short of it: early response predicts longer-term outcomes in pediatric weight management. Obesity (Silver Spring). 2019;27(2):272-279. doi:10.1002/oby.22367

21. The TODAY Study Group. A clinical trial to maintain glycemic control in youth with type 2 diabetes. $N$ Engl J Med. 2012;366 (24):2247-2256.

22. Inge TH, Laffel LM, Jenkins TM, et al. Comparison of surgical and medical therapy for type 2 diabetes in severely obese adolescents. JAMA Pediatr. 2018;172(5):452-460. doi:10.1001/jamapediatrics.20 17.5763

23. Inge TH, Courcoulas AP, Jenkins TM, et al. Weight Loss and Health Status 3 Years after Bariatric Surgery in Adolescents. $N$ Engl J Med. 2016;374(2):113-123. doi:10.1056/NEJMoa1506699

24. Styne DM, Arslanian SA, Connor EL, et al. Pediatric obesity-assessment, treatment, and prevention: an endocrine society clinical practice guideline. J Clin Endocrinol Metab. 2017;102 (3):709-757.

25. Mingrone G. Pros and cons of bariatric surgery in adolescents. Lancet Diabetes Endocrinol. 2017;5(3):152-154. doi:10.1016/S22138587(16)30425-9

26. Cummins CB, Nunez Lopez O, Hughes BD, et al. Adolescent bariatric surgery: effects of socioeconomic, demographic, and hospital characteristics on cost, length of stay, and type of procedure performed. Obes Surg. 2019;29(3):757-764. doi:10.1007/s11695018-03657-8

27. Andela S, Burrows TL, Baur LA, Coyle DH, Collins CE, Gow ML. Efficacy of very low-energy diet programs for weight loss: a systematic review with meta-analysis of intervention studies in children and adolescents with obesity. Obes Rev. 2019;20 (6):871-882. doi:10.1111/obr.12830

28. Academy of Nutrition and Dietetics. Pediatric Weight Management (PWM) guideline; 2007. Available from: https://www.andeal.org/ topic.cfm?menu=5296\&cat=2721. Accessed December 19, 2019.

29. Mustajoki P, Pekkarinen T. Very low energy diets in the treatment of obesity. Obes Rev. 2001;2(1):61-72. doi:10.1046/j.1467789x.2001.00026.x

30. Sumithran P, Prendergast LA, Delbridge E, et al. Ketosis and appetite-mediating nutrients and hormones after weight loss. Eur J Clin Nutr. 2013;67(7):759-764. doi:10.1038/ejen.2013.90

31. Delbridge E, Proietto J. State of the science: VLED (Very Low Energy Diet) for obesity. Asia Pac J Clin Nutr. 2006;15 Suppl (Suppl):49-54.

32. Gibson AA, Franklin J, Pattinson AL, et al. Comparison of very low energy diet products available in Australia and how to tailor them to optimise protein content for younger and older adult men and women. Healthcare. 2016;4(3):71. doi:10.3390/healthcare4030071

33. National Health and Medical Research Council. Clinical Practice Guidelines for the Management of Overweight Obesity in Adults, Adolescents and Children in Australia. Melbourne: National Health and Medical Research Council; 2013.

34. Willi SM, Martin K, Datko FM, Brant BP. Treatment of type 2 diabetes in childhood using a very-low-calorie diet. Diabetes Care. 2004;27(2):348-353. doi:10.2337/diacare.27.2.348

35. Gow ML, Baur LA, Johnson NA, Cowell CT, Garnett SP. Reversal of type 2 diabetes in youth who adhere to a very-low-energy diet: a pilot study. Diabetologia. 2017;60(3):406-415. doi:10.1007/s00125-0164163-5
36. Parretti HM, Jebb SA, Johns DJ, Lewis AL, Christian-Brown AM, Aveyard P. Clinical effectiveness of very-low-energy diets in the management of weight loss: a systematic review and meta-analysis of randomized controlled trials. Obes Rev. 2016;17(3):225-234. doi:10.1111/obr.12366

37. Ein N, Armstrong B, Vickers K. The effect of a very low calorie diet on subjective depressive symptoms and anxiety: meta-analysis and systematic review. Int $J$ Obes (Lond). 2019;43(7):1444-1455. doi:10.1038/s41366-018-0245-4

38. Harper C, Maher J, Grunseit A, Seimon RV, Sainsbury A. Experiences of using very low energy diets for weight loss by people with overweight or obesity: a review of qualitative research. Obes Rev. 2018;19(10):1412-1423. doi:10.1111/obr.12715

39. Lim EL, Hollingsworth KG, Aribisala BS, Chen MJ, Mathers JC, Taylor R. Reversal of type 2 diabetes: normalisation of beta cell function in association with decreased pancreas and liver triacylglycerol. Diabetologia. 2011;54(10):2506-2514. doi:10.1007/ s00125-011-2204-7

40. Snel M, Jonker JT, Hammer S, et al. Long-term beneficial effect of a 16 -week very low calorie diet on pericardial fat in obese type 2 diabetes mellitus patients. Obesity (Silver Spring). 2012;20 (8):1572-1576. doi:10.1038/oby.2011.390

41. Malandrucco I, Pasqualetti P, Giordani I, et al. Very-low-calorie diet: a quick therapeutic tool to improve beta cell function in morbidly obese patients with type 2 diabetes. Am J Clin Nutr. 2012;95 (3):609-613. doi:10.3945/ajcn.111.023697

42. Lean ME, Leslie WS, Barnes AC, et al. Primary care-led weight management for remission of type 2 diabetes (DiRECT): an open-label, cluster-randomised trial. Lancet. 2018;391 (10120):541-551. doi:10.1016/S0140-6736(17)33102-1

43. Lean MEJ, Leslie WS, Barnes AC, et al. Durability of a primary care-led weight-management intervention for remission of type 2 diabetes: 2-year results of the DiRECT open-label, cluster-randomised trial. Lancet Diabetes Endocrinol. 2019;7 (5):344-355. doi:10.1016/S2213-8587(19)30068-3

44. Xin Y, Davies A, Briggs A, et al. Type 2 diabetes remission: 2 year within-trial and lifetime-horizon cost-effectiveness of the Diabetes Remission Clinical Trial (DiRECT)/counterweight-plus weight management programme. Diabetologia. 2020;63(10):2112-2122. doi:10.1007/s00125-020-05224-2

45. Al-Mrabeh A, Zhyzhneuskaya SV, Peters C, et al. Hepatic lipoprotein export and remission of human type 2 diabetes after weight loss. Cell Metab. 2020;31(2):233-249 e234. doi:10.1016/j.cmet.2019.11.018

46. Yoshino M, Kayser BD, Yoshino J, et al. Effects of diet versus gastric bypass on metabolic function in diabetes. $N$ Engl J Med. 2020;383 (8):721-732. doi:10.1056/NEJMoa2003697

47. Huang YS, Zheng Q, Yang H, et al. Efficacy of intermittent or continuous very low-energy diets in overweight and obese individuals with type 2 diabetes mellitus: a systematic review and meta-analyses. J Diabetes Res. 2020;4851671. doi:10.1155/2020/ 4851671

48. Feinmann J. Type 2 diabetes: 5000 patients to test feasibility of "remission service". BMJ. 2018;363:k5114. doi:10.1136/bmj.k5114

49. Pfeiffle S, Pellegrino F, Kruseman M, et al. Current recommendations for nutritional management of overweight and obesity in children and adolescents: a structured framework. Nutrients. 2019;11(2):362. doi: 10.3390/nu11020362

50. Pena AS, Curran JA, Fuery M, et al. Screening, assessment and management of type 2 diabetes mellitus in children and adolescents: Australasian Paediatric Endocrine Group guidelines. Med $J$ Aust. 2020;213(1):30-43. doi:10.5694/mja2.50666

51. Smart CE, Annan F, Higgins LA, Jelleryd E, Lopez M, Acerini CL. ISPAD clinical practice consensus guidelines 2018: nutritional management in children and adolescents with diabetes. Pediatr Diabetes. 2018;19(Suppl 27):136-154. doi:10.1111/pedi.12738 
52. Copeland KC, Silverstein J, Moore KR, et al. Management of newly diagnosed type 2 Diabetes Mellitus (T2DM) in children and adolescents. Pediatrics. 2013;131(2):364-382. doi:10.1542/ peds.2012-3494

53. Jebeile H, Lister NB, Baur LA, Garnett SP, Paxton SJ. Eating disorder risk in adolescents with obesity. Obes Rev. 2020. doi:10.1111/ obr. 13173

54. Shulman EP, Smith AR, Silva K, et al. The dual systems model: review, reappraisal, and reaffirmation. Dev Cogn Neurosci. 2016;17:103-117. doi:10.1016/j.dcn.2015.12.010

55. Jones HM, Al-Khudairy L, Melendez-Torres GJ, Oyebode O. Viewpoints of adolescents with overweight and obesity attending lifestyle obesity treatment interventions: a qualitative systematic review. Obes Rev. 2019;20(1):156-169. doi:10.1111/obr.12771

56. Christensen P, Meinert Larsen T, Westerterp-Plantenga M, et al. Men and women respond differently to rapid weight loss: metabolic outcomes of a multi-centre intervention study after a low-energy diet in 2500 overweight, individuals with pre-diabetes (PREVIEW). Diabetes Obes Metab. 2018;20(12):2840-2851. doi:10.1111/ dom. 13466

57. Kistler KD, Molleston J, Unalp A, et al. Symptoms and quality of life in obese children and adolescents with non-alcoholic fatty liver disease. Aliment Pharmacol Ther. 2010;31(3):396-406. doi:10.1111/ j.1365-2036.2009.04181.x

58. Brown A, Leeds AR. Very low-energy and low-energy formula diets: effects on weight loss, obesity co-morbidities and type 2 diabetes remission - an update on the evidence for their use in clinical practice. Nutr Bull. 2019;44(1):7-24. doi:10.1111/nbu.12372

59. Rehackova L, Arnott B, Araujo-Soares V, Adamson AA, Taylor R, Sniehotta FF. Efficacy and acceptability of very low energy diets in overweight and obese people with Type 2 diabetes mellitus: a systematic review with meta-analyses. Diabet Med. 2016;33 (5):580-591. doi:10.1111/dme.13005
60. The TODAY Study Group.Binge eating, mood, and quality of life in youth with type 2 diabetes: baseline data from the today study. Diabetes Care. 2011;34(4):858-860.

61. Gow ML, Tee MSY, Garnett SP, et al. Pediatric obesity treatment, self-esteem, and body image: a systematic review with meta-analysis. Pediatr Obes. 2020;15(3):e12600. doi:10.1111/ijpo.12600

62. Jebeile H, Gow ML, Baur LA, Garnett SP, Paxton SJ, Lister NB. Association of pediatric obesity treatment, including a dietary component, with change in depression and anxiety: a systematic review and meta-analysis. JAMA Pediatr. 2019;173:e192841. doi:10.1001/ jamapediatrics.2019.2841

63. Jebeile H, Gow ML, Baur LA, Garnett SP, Paxton SJ, Lister NB. Treatment of obesity, with a dietary component, and eating disorder risk in children and adolescents: a systematic review with meta-analysis. Obes Rev. 2019;20(9):1287-1298. doi:10.1111/ obr. 12866

64. Isner JM, Sours HE, Paris AL, Ferrans VJ, Roberts WC. Sudden, unexpected death in avid dieters using the liquid-protein-modified-fast diet. Observations in 17 patients and the role of the prolonged QT interval. Circulation. 1979;60(6):1401-1412. doi:10.1161/01.CIR.60.6.1401

65. Sours HE, Frattali VP, Brand CD, et al. Sudden death associated with very low calorie weight reduction regimens. Am J Clin Nutr. 1981;34 (4):453-461. doi:10.1093/ajcn/34.4.453

66. Michiel RR, Sneider JS, Dickstein RA, Hayman H, Eich RH. Sudden death in a patient on a liquid protein diet. $N$ Engl J Med. 1978;298 (18):1005-1007. doi:10.1056/NEJM197805042981807

67. Lister NB, Gow ML, Chisholm K, Grunseit A, Garnett SP, Baur LA. Nutritional adequacy of diets for adolescents with overweight and obesity: considerations for dietetic practice. Eur J Clin Nutr. 2017;71 (5):646-651. doi:10.1038/ejen.2016.268

68. Lister NB, Jebeile H, Truby H, et al. Fast track to health - Intermittent energy restriction in adolescents with obesity. A randomised controlled trial study protocol. Obes Res Clin Pract. 2020;14(1):80-90. doi:10.1016/j.orcp.2019.11.005

Diabetes, Metabolic Syndrome and Obesity: Targets and Therapy

Dovepress

\section{Publish your work in this journal}

Diabetes, Metabolic Syndrome and Obesity: Targets and Therapy is an international, peer-reviewed open-access journal committed to the rapid publication of the latest laboratory and clinical findings in the fields of diabetes, metabolic syndrome and obesity research. Original research, review, case reports, hypothesis formation, expert opinion and commentaries are all considered for publication. The manuscript management system is completely online and includes a very quick and fair peer-review system, which is all easy to use. Visit http://www.dovepress.com/testimonials.php to read real quotes from published authors.

Submit your manuscript here: https://www.dovepress.com/diabetes-metabolic-syndrome-and-obesity-targets-and-therapy-journal 